\title{
Influence of light intensity and photoperiod on energy efficiency of biomass and pigment production of Spirulina (Arthrospira platensis) ${ }^{\text {is }}$
}

\author{
N'goran Urbain Florent Niangoran ${ }^{1,2, *}$, David Buso ${ }^{1}$, Georges Zissis ${ }^{1}$ and Thomas Prudhomme ${ }^{3}$ \\ ${ }^{1}$ LAboratoire PLAsma et Conversion d'Energie (LAPLACE), UPS, Université de Toulouse, 118 route de Narbonne, 31062 Toulouse \\ Cedex 9, France \\ ${ }^{2}$ Laboratoire de Physique Fondamentale et Appliquée (LPFA), Université Nangui Abrogoua, 02 BP 801, Abidjan 02, Côte d'Ivoire \\ ${ }^{3}$ Biosentec, 48 Chemin des Palanques Sud, 31120 Portet-sur-Garonne, France
}

Received 30 March 2021 - Accepted 21 June 2021

\begin{abstract}
Biomass and photosynthetic pigments production of cyanobacteria, in particular Spirulina (Arthrospira platensis), depend on light intensity. Production cost of Spirulina cultivation in photobioreactor illuminated with LED is strongly related to light cost. This work is aimed to evaluate the effects of light intensity and photoperiod on the energy efficiency of biomass and pigment production of Spirulina platensis UTEX 1926. Cultures illuminated with white light-emitting diodes (LED) were carried out in batch mode cultivation. Three lighting scenarios with different light intensities were tested: two with a constant light intensity at 80 and $160 \mu \mathrm{mol} \cdot \mathrm{m}^{-2} \cdot \mathrm{s}^{-1}$ and one with modulated light intensity. Concerning photoperiod, three cycles of light:dark (h:h) (24:00, 20:04 and 16:08) were studied under light intensity at $160 \mu \mathrm{mol} \cdot \mathrm{m}^{-2} \cdot \mathrm{s}^{-1}$. Concerning Spirulina biomass and pigment production (phycocyanin, chlorophyll and carotenoids), it is found that the lower intensity tested allows a substantial increase of the process energy efficiency. Concerning the influence of the photoperiod, it has been found that the longer the off time is (up to $08 \mathrm{~h} 00$ a day), the higher is the energy efficiency for Spirulina biomass as well as for pigmentary production.
\end{abstract}

Keywords: LED lighting / photoperiod / Spirulina cultivation / phycocyanin / carotenoids

Résumé - Influence de l'intensité lumineuse et de la photopériode sur l'efficacité énergétique de la biomasse et la production de pigments de Spiruline (Arthrospira platensis). La production de biomasse et de pigments photosynthétiques à partir des cyanobactéries, en particulier la Spiruline, dépend de l'intensité lumineuse. Le coût de production de la culture de la Spiruline dans un photobioréacteur éclairé par des LED est fortement lié au coût de la lumière. Ce travail vise à évaluer les effets de l'intensité de la lumière et de la photopériode sur l'efficacité énergétique de la biomasse et de la production de pigments de Spiruline platensis. Les cultures éclairées avec des diodes électroluminescentes blanches (LED) ont été réalisées en mode batch. Trois scénarios d'éclairage avec des intensités lumineuses différentes ont été testés : deux avec une intensité lumineuse constante à 80 et $160 \mu \mathrm{mol} \cdot \mathrm{m}^{-2} \cdot \mathrm{s}^{-1}$ et un avec une intensité lumineuse modulée. Concernant la photopériode, trois cycles de lumière : obscurité (h:h) (24:00, 20:04 et 16:08) ont été étudiés sous une intensité lumineuse à $160 \mu \mathrm{mol} \cdot \mathrm{m}^{-2} \cdot \mathrm{s}^{-1}$. Concernant la biomasse de Spiruline et la production de pigments (phycocyanine, chlorophylle et caroténoïdes), on constate que la plus faible intensité lumineuse testée permet d'augmenter considérablement l'efficacité énergétique du procédé. Concernant l'influence de la photopériode, il a été constaté que plus le temps de non-éclairage est long (jusqu'à $08 \mathrm{~h} 00$ par jour), plus l'efficacité énergétique est élevée pour la biomasse de Spiruline ainsi que pour la production de pigments.

Mots clés : éclairage LED / photopériode / Culture Spiruline / phycocyanine / caroténoïdes

\footnotetext{
Contribution to the Topical Issue "Green and white biotechnologies in the fields of lipids and oil- and protein crops / Biotechnologies vertes et blanches dans les domaines des lipides et oléoprotéagineux".

*Correspondence: niangoran@laplace.univ-tlse.fr; urbain_niangoran@yahoo.fr
} 


\section{Highlights}

- Energy efficiency of Spirulina platensis biomass and pigment production (carotenoids, chlorophyll and phycocyanin) is strongly related to light (including light intensity and photoperiod).

- Energy savings is achieved while preserving high production rate for both biomass and pigments by adjusting light level as cell concentration increases.

\section{Introduction}

Microalgae are potential sources of biomass production. They have many and various applications including food and feed, cosmetic and pharmaceutical industry. In addition, these microorganisms are considered as a promising source of biofuels (Becker, 2007; Carvalho et al., 2011; Blanken et al., 2013). Among the valuable microalgae, we can mention Spirulina. Indeed, Spirulina can contain 60 to $70 \%$ of proteins in dry weight. It is rich in vitamins, especially vitamins B12, provitamin A and minerals, in particular iron (Bezerra et al., 2011). Incorporating Spirulina biomass into food helps to increase its nutritional value (Koru, 2012). It is an important source of valuable pigments like chlorophyll a (Chl-a), carotenoids and phycobiliproteins (especially phycocyanin (Phy)) (Boussiba and Richmond, 1980). Phycocyanin is a very important pigment because it may be used in many applications. In the food industry, it is used as a natural blue food colouring. In biotechnology field, it serves as a fluorescent marker. It has neuroprotective, anti-inflammatory and antioxidant properties (Bhat and Madyastha, 2000; Romay et al., 2003). As for chlorophyll, in addition to its health benefits (antioxidant, anti-inflammatory, antimutagenic, and antimicrobial properties) (Galasso et al., 2019), it is also used as a colouring. Among the sources of chlorophyll production (plants, microalgae, etc.), Spirulina presents one of the highest chlorophyll content (Koru, 2012). Finally, Spirulina also contains carotenoids (known for its antioxidant effects) with a prominent amount of $\beta$-carotene (67 to $79 \%$ in carotenoids pigment group). Consuming carotenoids in form of provitamin A or $\beta$-carotene improves the immune system and reduces the risk of developing chronic degenerative diseases, cardiovascular diseases and certain types of cancer (RodríguezConcepcíon et al., 2018).

Microalgae can be cultured by different methods of nutrient supply for their growth: autotrophic, heterotrophic, mixotrophic and photoautotrophic (Chojnacka and Noworyta, 2004). The photoautotrophic or mixotrophic growth of microalgae requires $\mathrm{CO}_{2}$ and light for the realization of photosynthesis. Light energy can be provided by natural lighting (sun) or artificial lighting (lamps). In controlled growing environments such as indoor bioreactors, the use of artificial light is obligatory. Artificial lighting generally gives the possibility of controlling light intensity and the lighting time. Although artificial lighting can increase productivity, it also generates additional costs. Thus, optimal use in terms of photosynthesis, energy efficiency and spectral composition can provide a wider and cheaper range of high benefit products obtained from microalgae biomass. In this respect, LED lighting technologies are in vogue compared to conventional technologies (halogen lamp, fluorescent lamp lamps, highpressure sodium lamp, etc.). The main reasons are its monochromatic spectrum and dimmable intensity. These characteristics of LEDs are their main assets compared to other light sources. Indeed, these make it possible to evaluate efficiency of dimmed lighting for microalgae cultivation. In addition, cultures of microalgae cultivation are generally carried out under constant light intensity. Modulation of light intensity according to the cell density of Spirulina could be promising. Thus, this lighting technique could make it possible to save electrical energy. Moreover, a long lifetime and a high electrical efficiency of LED minimize heat generation. Their low heat production makes it possible to bring them closer to the crop, thus increasing the path of light. Finally, their small sizes allow them to be integrated practically in all growth systems, especially photobioreactors.

Several research works show the efficiency of LED lighting in microalgae culture including Spirulina (Schulze et al., 2014; Glemser et al., 2016). They also indicate that light intensity, spectrum and photoperiod have considerable effects on growth and biochemical composition (in particular pigment contents) of Spirulina. Light intensity and spectrum are thus key factors that can be tuned to match the whole or a particular absorption band to act on quantity and/or quality production of biomass and pigments. It is commonly accepted that red and white lights promote high quantities of biomass while high intensity light and blue light enhance phycocyanin production. Literature also mentions that green light is harmful for pigments production except phycocyanin. Moreover, for light intensities lower than the saturation and photo-inhibition lights, biomass quantity increases with light quantity (Pareek and Srivastava, 2001; Madhyastha and Vatsala, 2007; Madhyastha et al., 2009; Chen et al., 2010; Kumari et al., 2015; Tian et al., 2018). However, process energy efficiency is still an issue and has not been extensively discussed yet. The aim of this work is to investigate, in terms of energy efficiency and productivity, biomass production and photosynthetic pigment contents in Spirulina platensis under different light intensities, including dimmed light conditions and different photoperiods.

\section{Materials and methods}

\subsection{Microorganism and culture conditions}

Spirulina species used in this study was Arthrospira platensis (UTEX 1926) and was grown in Zarrouk medium (Zarrouk, 1966). The strain culture was grown in cylindrical tanks of $60 \mathrm{~L}$ at $28^{\circ} \mathrm{C}$ with continuous illumination at $200 \mu \mathrm{mol} \cdot \mathrm{m}^{-2} \cdot \mathrm{s}^{-1}$ provided by warm white $(3000 \mathrm{~K}) \mathrm{LED}$ tube lamp (MAS LEDtube HF $600 \mathrm{~mm}$ HE 8W 830 T5 from Philips). The light intensity corresponds to the photosynthetic photon flux density (PPFD). PPFD is a light measuring system that best responds to the study of light action in photosynthetic activity because it takes into account relative quantum efficiency (RQE) (McCree, 1971). Photometry is not suitable because it is based on the sensitivity to light of human eye 
which differs from that of plants (Biggs, 1986). This lamp has been modified to be dimmable. Strain culture is agitated by a circulating pump. For inoculation, we took a certain amount of the strain culture, and filtered it by a $30 \mu \mathrm{m}$ strainer, then diluted the $S$. platensis with Zarrouk. Photoautotrophic cultures were made in cylindrical tanks of $25 \mathrm{~L}$ in batch mode. In addition, they were illuminated with LED lamps (Maxline70 Warm white LED strip from lumitronix). The value of photosynthetic photon flux density (PPFD) was measured by the spectroradiometer Specbos 1201. Cultures were agitated with circular pumps (LAGUNA pump with a flow velocity of $5000 \mathrm{~L} / \mathrm{h}$ ). Thermostats (NICREW aquarium heater $100 \mathrm{~W}$ ) were used to keep the cultures at $28^{\circ} \mathrm{C}$.

Regarding the influence of light intensity modulation on Spirulina growth and pigment contents, three lighting scenarios were tested:

- scenario 1: constant light intensity at $80 \mu \mathrm{mol} \cdot \mathrm{m}^{-2} \cdot \mathrm{s}^{-1}$;

- scenario 2: constant light intensity at $160 \mu \mathrm{mol} \cdot \mathrm{m}^{-2} \cdot \mathrm{s}^{-1}$;

- scenario 3: modulated light intensity illumination $\left(80 \mu \mathrm{mol} \cdot \mathrm{m}^{-2} \cdot \mathrm{s}^{-1}\right.$ during two first days and $160 \mu \mathrm{mol} \cdot \mathrm{m}^{-2} \cdot \mathrm{s}^{-1}$ afterwards).

Regarding the photoperiods, we examined three light:dark (h:h) cycles: 24:00, 20:04 and 16:08 under light intensity at $160 \mu \mathrm{mol} \cdot \mathrm{m}^{-2} \cdot \mathrm{s}^{-1}$.

Measurements were performed in triplicate and results were expressed as mean $\pm 95 \%$ confidence interval, i.e.: $\mathrm{m} \pm \mathrm{ts} / \mathrm{sqrt}(\mathrm{n})$ where $m$ is the mean of the $n$ values $(n=3)$, $s$ is the estimated standard deviation and $\mathrm{t}$ is given by the Student-Fisher distribution for $95 \%$ of confidence interval and a degree of freedom of $n-1$.

\subsection{Biomass analysis}

Spirulina platensis Biomass was determined by measuring the optical density (OD) at $600 \mathrm{~nm}$ using UV/Visible/IR spectrophotometer (Spectronic 20 GeneisSYS, Spectronic Instruments, USA). Then a linear equation was established between biomass dry weight (DW, g. L-1) and the optical density at $600 \mathrm{~nm}$. It follows the same protocol as Lee et al. (2016).

\subsubsection{Kinetic and others parameters}

Arthrospira platensis specific growth rate $\mu\left(\right.$ day $\left.^{-1}\right)$ is calculated during the 8 days of cultivation according to equation (1) (Wang et al., 2007):

$$
\mu=\frac{\ln \left(\mathrm{DW}_{2}\right)-\ln \left(\mathrm{DW}_{1}\right)}{\mathrm{t}_{2}-\mathrm{t}_{1}},
$$

where $\mathrm{DW}_{2}$ and $\mathrm{DW}_{1}$ are the dry weights of biomass on days $\mathrm{t}_{2}$ and $t_{1}$, respectively.

We calculated biomass production $\mathrm{P}\left(\mathrm{mg} \cdot \mathrm{L}^{-1} \cdot\right.$ day $\left.^{-1}\right)$ (Eq. (2)) (Wang et al., 2007) and energy efficiency $\eta$ $\left(\mathrm{g} \cdot \mathrm{day}^{-1} \cdot \mathrm{kWh}^{-1}\right)$ of electrical energy to biomass production (Eq. (3)):

$$
\mathrm{P}=1000 \cdot \frac{\mathrm{DW}_{\mathrm{n}}-\mathrm{DW}_{\mathrm{w}_{0}}}{\mathrm{~T}},
$$

$$
\eta=\frac{\mathrm{DW}_{\mathrm{n}}-\mathrm{DW}_{\mathrm{w}}}{\mathrm{T} \cdot \mathrm{E}_{\mathrm{e}}} \cdot \mathrm{V},
$$

where $\mathrm{DW}_{0}$ and $\mathrm{DW}_{\mathrm{n}}$ are respectively the dry weights of biomass on initial and $n$th day of cultivation, $\mathrm{V}(\mathrm{L})$ is volume of culture and $E_{e}(\mathrm{kWh})$ is electrical energy consumed by LEDs during cultivation time $\mathrm{T}$ (days).

\subsubsection{Pigments quantification}

Chlorophyll a and carotenoids were assayed using the method of Lichtenthaler (1987). The $1.8 \mathrm{~mL}$ of microalgae solution was centrifuged at $10000 \times \mathrm{g}$ for $15 \mathrm{~min}$. After discarding the supernatant, $1.8 \mathrm{~mL}$ of $99.8 \%$ methanol solution was added to fresh biomass, mixed well and incubated at $4{ }^{\circ} \mathrm{C}$ for $24 \mathrm{~h}$ in darkness. Then, sample was exposed at room temperature for $4 \mathrm{~h}$ in darkness. Finally, it was homogenized during $2 \mathrm{~min}$ by ZX3 Vortex Agitator at $2000 \mathrm{tr} / \mathrm{min}$. Then, it was centrifuged at $20^{\circ} \mathrm{C}, 4000 \times \mathrm{g}$ for $10 \mathrm{~min}$ before spectrophotometric measuring. The $\mathrm{Chl}-\mathrm{a}$ and carotenoids concentrations were calculated according to equations (4) and (5):

$$
\mathrm{Chl}-\mathrm{a}\left(\mathrm{mg} \cdot \mathrm{L}^{-1}\right)=16.72 * \mathrm{~A}_{665}-9.16 * \mathrm{~A}_{652},
$$

Carotenoid $\left(\mathrm{mg} \cdot \mathrm{L}^{-1}\right)=\left(1000 * \mathrm{~A}_{470}-1.63 * \mathrm{Chl}-\mathrm{a}\right) / 221$,

where $\mathrm{A}_{665}, \mathrm{~A}_{652}$ and $\mathrm{A}_{470}$ are the absorbance readings at 665 , 652 and $470 \mathrm{~nm}$.

Phycocyanin was determined according to Bennett and Bogorad (1973). As for Chl-a and carotenoids, $1.8 \mathrm{~mL}$ of microalgae cells was centrifuged at $10000 \times \mathrm{g}$ for $15 \mathrm{~min}$. After discarding the supernatant, $1.8 \mathrm{~mL}$ of $1.5 \% \mathrm{CaCl}_{2}(\mathrm{~W} / \mathrm{V})$ solution was added to fresh biomass. Four freeze/thawing cycles were performed on fresh biomass (incubation at $-20^{\circ} \mathrm{C}$ for $24 \mathrm{~h}$ in darkness followed by $4 \mathrm{~h}$ in darkness at room temperature). Finally, it was homogenized during $2 \mathrm{~min}$ by ZX3 Vortex Agitator at $2000 \mathrm{tr} / \mathrm{min}$ and centrifuged at $20^{\circ} \mathrm{C}$, $4000 \times \mathrm{g}$ for $10 \mathrm{~min}$ before spectrophotometric measuring. The Phy concentration was calculated according to equation (6):

$$
\operatorname{Phy}\left(\mathrm{g} \cdot \mathrm{L}^{-1}\right)=\left(\mathrm{A}_{615}-0.474 * \mathrm{~A}_{652}\right) / 5.34,
$$

where $A_{615}$ is the optical density at $615 \mathrm{~nm}$.

The calculated pigment contents are those of the eighth day.

\section{Results and discussion}

\subsection{Effect of modulated light intensity on Spirulina growth and pigment content}

\subsubsection{Biomass production}

Light is the basic source of energy and an important factor of photosynthesis for the cellular multiplication of microalgae. In photoautotrophic regime, light is essential for microalgae growth (Wahidin et al., 2013). In the present work, no light inhibition was found for the range of intensities tested. 


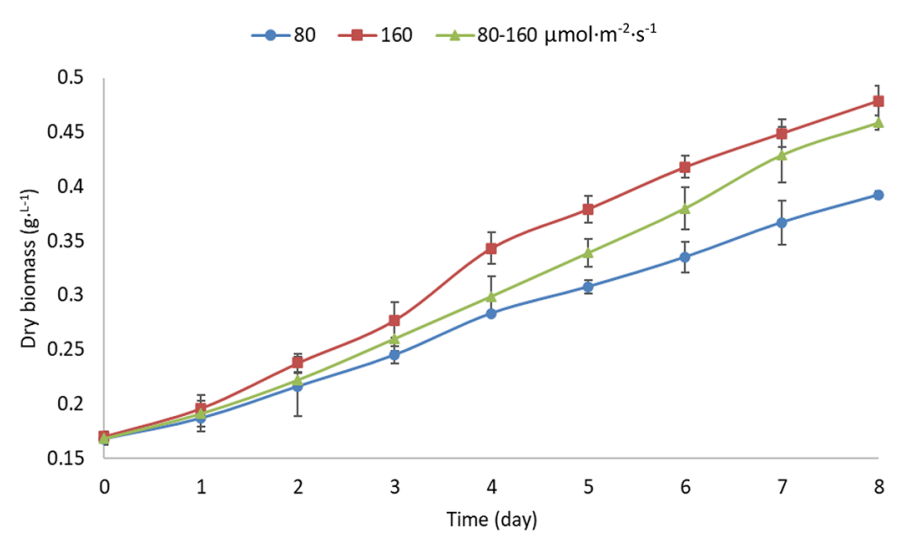

Fig. 1. Biomass produced of Arthrospira platensis growth according to the three lighting scenarios.

It should also be noted that for each scenario, no lag phase has been observed. This is consistent with the fact that the lag phase duration depends essentially on culture medium and not on light conditions. According to the differences of the culture medium with the inoculum culture medium, this phase may be observed.

Figures 1 and 2 illustrate observations of the cell growth of Spirulina platensis for the three scenarios described above for 8 days of cultivation. The lowest biomass production was obtained with scenario 1 (constant light intensity at $\left.80 \mu \mathrm{mol} \cdot \mathrm{m}^{-2} \cdot \mathrm{s}^{-1}\right)$, while the highest was obtained in runs with scenario 2 (constant light intensity at $160 \mu \mathrm{mol} \cdot \mathrm{m}^{-2} \cdot \mathrm{s}^{-1}$ ) and scenario 3 (modulated light intensity $80-160 \mu \mathrm{mol} \cdot \mathrm{m}^{-2}$. $\mathrm{s}^{-1}$ ) (Fig. 1). This is in line with previous works where it was demonstrated that specific growth rate of microalgae is proportional to light intensity, up to saturation levels (Qiang et al., 1998; Wang et al., 2007; Dubinsky, 2013; Rizzo et al., 2015). For scenario 3 , light intensity was changed from 80 to $160 \mu \mathrm{mol} \cdot \mathrm{m}^{-2} \cdot \mathrm{s}^{-1}$ after two days of cultivation to evaluate how dynamic light intensity adjustment affects the Spirulina growth in terms of productivity and energy efficiencies. Indeed, up to days 2 a small growth gap between scenarios 1 and 2 can be observed and shows that it is not necessary to illuminate cultures at high light intensities at the beginning of cultivation.

It can be seen that the increase of light intensity does not have an immediate effect on Spirulina growth as there is no significant biomass increase up to day 4 . These results suggest that there is a period of adaptation of cells to a change (especially an increase) in light intensity (Danesi et al., 2004; Patel et al., 2019).

It can also be observed that the growth rate in scenarios 1 and 2 drops drastically down after four days of cultivation while it decreases slowly and monotonically in scenario 3 (Fig. 2). In scenarios 1 and 2, average growth rate between days 1 and 4 passes respectively from 0.1311 and 0.1757 day $^{-1}$ to 0.0814 and 0.0833 day $^{-1}$ between days 5 to 8 (drop of $38 \%$ and $52 \%$ respectively). For comparison in scenario 3 average growth rate passes from $0.1439 \mathrm{day}^{-1}$ to $0.1069 \mathrm{day}^{-1}$ (drop of $26 \%$ ). The higher average growth rate between days 5 and 8 explains that final dry biomass obtained with scenario 3 is only $4.18 \%$ lower than the one obtained with scenario 2 .

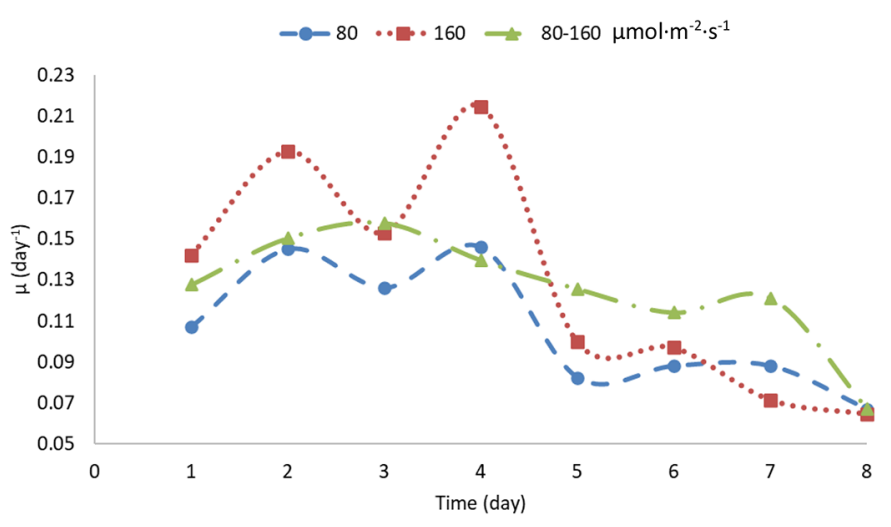

Fig. 2. Growth rates of Arthrospira platensis growth according to the three lighting scenarios.

These observations suggest that dynamically increasing light intensity as cell concentration increases may be a promising option for energy savings. Indeed, this type of lighting makes it possible to illuminate culture during first days with low light intensities without negatively impacting Spirulina growth. Also, it could make it possible to avoid using saturation light. With intensities of saturation lights, lighting is not optimal because their photosynthetic yields are identical (Qiang et al., 1998).

Table 1 presents the average growth rate values, biomass productivities and energy efficiencies for different lighting scenarios. Productivity and specific growth rate were maximal for scenarios 2 and 3. Biomass productivities with scenarios 2 and 3 are $35 \%$ higher than with scenario 1 . However, the highest energy efficiency is obtained for scenario 1. Actually, there is a light intensity range (low PPFD range) for which biomass productivity is proportional to light intensity (Chojnacka and Noworyta, 2004; Xue et al., 2011). We can assume here that at $160 \mu \mathrm{mol} \cdot \mathrm{m}^{-2} \cdot \mathrm{s}^{-1}$, the light intensity is near to or is a saturation intensity. Indeed, within the saturation light range, photosynthetic activity is almost constant and a significant part of absorbed photons are not used (Qiang et al., 1998). Moreover, even if no photo-inhibition has been observed at $160 \mu \mathrm{mol} \cdot \mathrm{m}^{-2} \cdot \mathrm{s}^{-1}$, it is possible that this light intensity is high enough to create light stress at the start of culture according our inoculation concentration. This may cause a lower process energy efficiency. Indeed, an excess light can occur when the ratio of PPFD to photosynthesis is high. Thus, at a constant PPFD, this ratio is high at the beginning of the cultivation (low photosynthetic cell concentration) and decreases gradually for increasing cell concentration (Demmig-Adams and Adams, 1992). Compared to scenario 2, the productivity obtained with scenario 3 is $5.93 \%$ lower but energy efficiency is $7.92 \%$ higher. This result shows that dynamically adjusting light intensity may be a good way to improve culture process efficiency while preserving high productivities. This principle has to be investigated in more details and can be done for instance by continuously adjusting the light intensity according to the optical density of the culture medium. 
Table 1. Average growth rates, biomass productivities and energy efficiencies of three lighting scenarios.

\begin{tabular}{llll}
\hline Light intensity $\left(\mu \mathrm{mol} \cdot \mathrm{m}^{-2} \cdot \mathrm{s}^{-1}\right)$ & $\mu_{\mathrm{av}}\left(\mathrm{day}^{-1}\right)$ & $\mathrm{P}\left(\mathrm{mg} \cdot \mathrm{L}^{-1} \cdot \mathrm{day}^{-1}\right)$ & $\eta\left(\mathrm{g} \cdot \mathrm{day}^{-1} \cdot \mathrm{kWh} \mathrm{Wh}^{-1}\right)$ \\
\hline 80 & $0.1070 \pm 0.0038$ & $28.38 \pm 0.82$ & $1.48 \pm 0.05$ \\
160 & $0.1295 \pm 0.0008$ & $38.63 \pm 1.12$ & $1.01 \pm 0.03$ \\
$80-160$ & $0.1254 \pm 0.0030$ & $36.34 \pm 0.20$ & $1.09 \pm 0.03$ \\
\hline
\end{tabular}

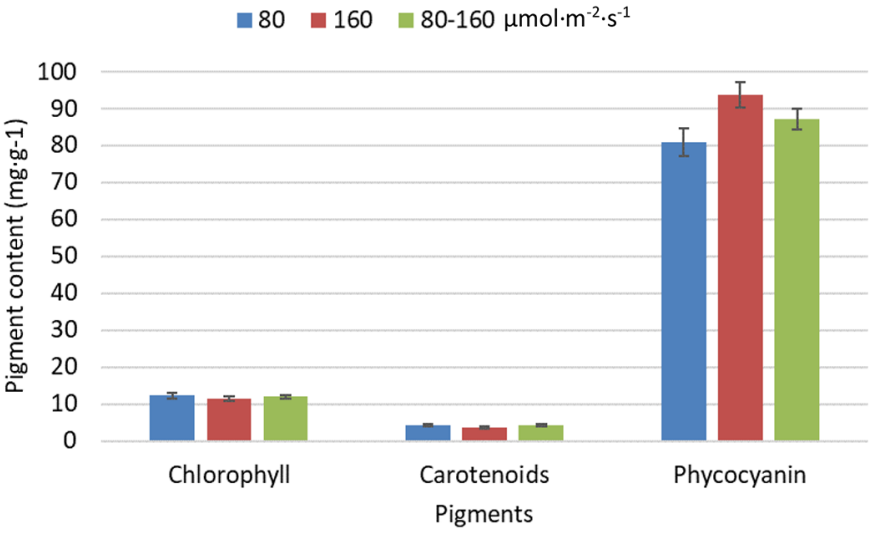

Fig. 3. Arthrospira platensis pigment content for three lighting scenarios.

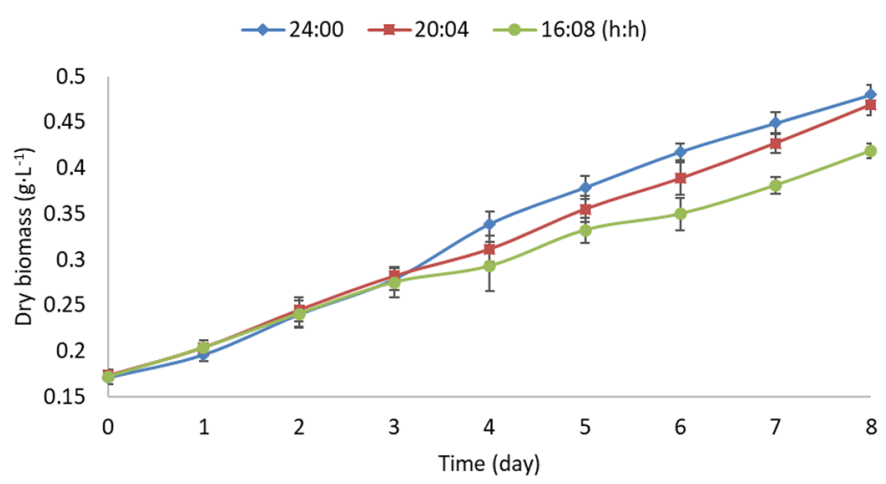

Fig. 4. Arthrospira platensis growth curves as a function of different photoperiods.

Table 2. Energy efficiencies of pigmentary production and light intensities.

\begin{tabular}{llrr}
\hline Light intensity $\left(\mu \mathrm{mol} \cdot \mathrm{m}^{-2} \cdot \mathrm{s}^{-1}\right)$ & \multicolumn{2}{c}{ Energy efficiencies $\eta\left(\mathrm{mg} \cdot \mathrm{day}{ }^{-1} \cdot \mathrm{kWh}^{-1}\right)$} \\
\cline { 2 - 5 } & Chl-a & Carotenoids & Phy \\
\hline 80 & $1.27 \pm 0.08$ & $0.44 \pm 0.03$ & $8.254 \pm 0.17$ \\
$80-160$ & $0.73 \pm 0.04$ & $0.24 \pm 0.02$ & $5.92 \pm 0.32$ \\
\hline
\end{tabular}

\subsubsection{Pigment production}

To understand the relationships between pigment concentrations under different light intensities, chlorophyll, carotenoids and phycocyanin contents were measured and recorded, as shown in Figure 2. We observed that light intensities have a more or less pronounced influence on the concentrations of the different pigments.

For carotenoids and chlorophyll, the light intensity has a limited effect. The lighting scenarios 1,2 and 3 give respectively $12.29,11.48$ and $12.09 \mathrm{mg} \cdot \mathrm{g}^{-1}$ of Chl content per dry matter (Fig. 3). Concerning carotenoids concentration, the lighting scenario 1 provides slightly higher rates compared to scenarios 2 and 3 (respectively $13.52 \%$ and $9.02 \%$ more). It is consistent with the results of Kumar et al. (2011). Other authors, such as Ravelonandro et al. (2008), Chen et al. (2010) and Danesi et al. (2011), mentioned that they observed a decrease of chlorophyll and carotenoids concentration with an increasing light intensity. Indeed, the increase of light intensity induces a decrease in the photosystem concentration of the thylakoid membrane and a decrease in the size of the photosystem II (PSII). However, despite a decrease in the chlorophyll content, we can observe an increase in photosynthetic activity because the capacity of absorption and conversion of photons into chemical energy by chlorophyll remains, or even greatly increases. In addition, in the case of too strong and prolonged light intensity, photo-inhibition causes destruction of photosynthetic pigments by photooxidation (Hendry et al., 1987; Alves et al., 2002). Finally, in some cases, the initiation of the xanthophylls cycle (pigment belonging to the carotenoids family) is then the main protection which allows to dissipate the energy absorbed by the chlorophylls at the PSII antenna in the form of heat.

Unlike the two previous pigments, effect of light intensity on phycocyanin concentration is more significant. Scenario 2 (constant light intensity at $160 \mu \mathrm{mol} \cdot \mathrm{m}^{-2} \cdot \mathrm{s}^{-1}$ ) promotes a higher production of phycocyanin. The difference of phycocyanin content between scenarios 2 and 3 is $7.86 \mathrm{mg} \cdot \mathrm{g}^{-1}$ $(8.39 \%)$. This result is consistent with literature (Chen'v et al., 1996; Chen et al., 2013) where it was observed that phycocyanin content increases with increasing light intensity.

Energy efficiencies of the different scenarios are presented in Table 2. We can observe that scenario 1 (i.e. constant lighting intensity at $80 \mu \mathrm{mol} \cdot \mathrm{m}^{-2} \cdot \mathrm{s}^{-1}$ ), gives the highest energy efficiencies for pigments production. Overall, in terms 
Table 3. Growth rates, biomass productivities and energy efficiencies following photoperiod.

\begin{tabular}{llll}
\hline Photoperiod $(\mathrm{h}: \mathrm{h})$ & $\mu_{\max }\left(\mathrm{day}^{-1}\right)$ & $\mathrm{P}\left(\mathrm{g} \cdot \mathrm{L}^{-1} \cdot \mathrm{day}^{-1}\right)$ & $\eta\left(\mathrm{g} \cdot \mathrm{day}^{-1} \cdot \mathrm{kWh}^{-1}\right)$ \\
\hline $24: 00$ & $0.1290 \pm 0.0020$ & $38.63 \pm 1.13$ & $1.01 \pm 0.03$ \\
$20: 04$ & $0.1244 \pm 0.0025$ & $36.96 \pm 1.29$ & $1.16 \pm 0.04$ \\
$16: 08$ & $0.1117 \pm 0.0063$ & $30.88 \pm 1.47$ & $1.21 \pm 0.05$ \\
\hline
\end{tabular}

of chlorophyll a and carotenoids contents, the energy efficiency is almost twice higher compared to other scenarios. For phycocyanin scenario 1 is 1.4 times more efficient than scenarios 2 and 3 . There is no significant difference between scenarios 2 and 3 in terms of energy efficiency for pigment production.

\subsection{Effect of photoperiod on Spirulina growth and pigment content}

\subsubsection{Biomass production}

Biomass concentration of $S$. platensis was evaluated for different photoperiods during 8 days of cultivation for constant light intensity at $160 \mu \mathrm{mol} \cdot \mathrm{m}^{-2} \cdot \mathrm{s}^{-1}$ (Fig. 4). Maximum biomass productivity i.e. $38.63 \pm 1.13 \mathrm{~g} \cdot \mathrm{L}^{-1} \cdot$ day $^{-1}$ and minimum i.e. $30.88 \pm 1.47 \mathrm{~g} \cdot \mathrm{L}^{-1} \cdot$ day $^{-1}$ were respectively observed at light/dark 24:00 and 16:08 (Tab. 3). We observed that the higher the lighting time, the higher is the biomass production (Fig. 4). However, photoperiod 24:00 gives the lowest energy efficiency. Photoperiod 16:08 exhibits the highest energy efficiency. As in this experiment light intensity is the same, energy efficiency improvement comes from duration of dark phase. Moreover, high photosynthetic efficiencies are achieved when light/dark cycle period approaches turnover time of the photosynthetic unit (Richmond et al., 2003; Amini Khoeyi et al., 2012; Liao et al., 2014). Photosynthesis is carried out in two stages: light reactions and dark reactions. In light reactions, cyanobacteria use light to break down water molecule. This reaction produces chemical energy providing NADPH (nicotinamide adenine dinucleotide phosphate) and a highly energetic compound ATP (adenine tri-phosphate). NADPH2 and TP are necessary, in particular, for the assimilation of inorganic nutrients. In dark reactions or enzymatic reactions, cyanobacteria assimilate $\mathrm{CO}_{2}$ and produce carbohydrates, lipids (Wahidin et al., 2013). Thus, the dark reactions also occur during the lighting time especially when the culture is constantly illuminated. Part of the energy absorbed by the microalgae is therefore not used.

The dry biomass quantities after 8 days using photoperiods 24:00, 20:04 and 16:08 are 0.4800 $\pm 0.0110,0.4690 \pm 0.0115$ and $0.4194 \pm 0.0095 \mathrm{~g} \cdot \mathrm{L}^{-1}$ respectively. It can be seen that biomass production from 24 and $20 \mathrm{~h}$ of lighting is almost identical unlike a lighting time of $16 \mathrm{~h}$. Similar results were obtained in work on growth of Spirulina and other microalgae (Pareek and Srivastava, 2001; Wahidin et al., 2013). In addition, photoperiod 16:08 is respectively 1.20 and 1.04 times more efficient than photoperiod 24:00 and 20:04. Besides, when the exposure time of Spirulina cultures is less than $16 \mathrm{~h}$, the energy efficiency decreases and becomes almost constant after $16 \mathrm{~h}$ of lighting (Niangoran et al., 2018). Obtained results show that the best compromise between biomass productivity and energy efficiency for Spirulina growth is 20:04 h.

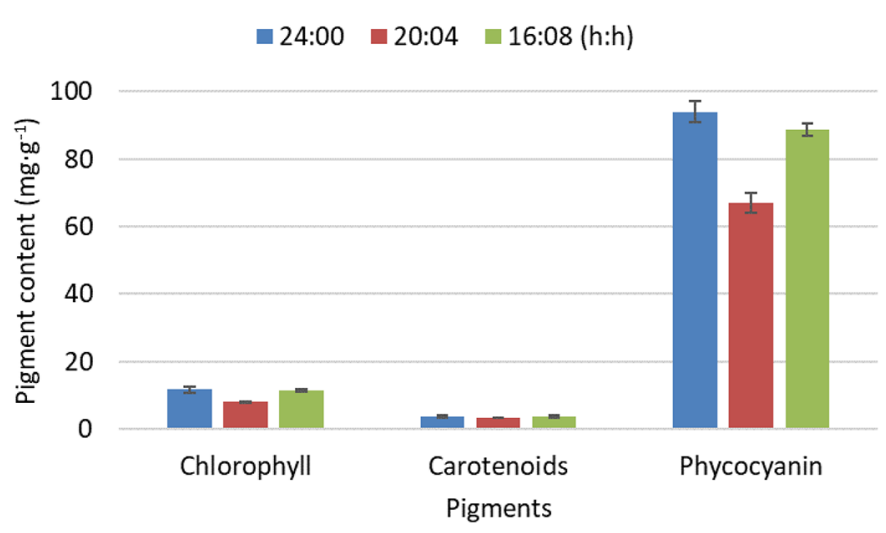

Fig. 5. Arthrospira platensis pigment content for different photoperiod treatment.

\subsubsection{Pigment production}

The effect of three different photoperiods (24:0, 20:00 and 16:08 light/dark) at light intensity $160 \mu \mathrm{mol} \cdot \mathrm{m}^{-2} \cdot \mathrm{s}^{-1}$ on pigment content of $S$. platensis for eight days of cultivation period is presented in Figure 5. Minimum concentration $\left(67.15 \pm 2.91 \mathrm{mg} \cdot \mathrm{g}^{-1}\right.$ of biomass dry weight $)$ of phycocyanin was obtained for 20:04. Phycocyanin concentration is improved by $39.95 \%$ with cycle $24: 00$ and by $32.12 \%$ with cycle 16:08. Lowest chlorophyll and carotenoids contents are also obtained with the photoperiod 20:04. Maximum content of these two pigments are obtained with 16:08 light/dark cycles. These results are consistent with study of Pareek and Srivastava (2001) who observed the same behaviour. However, differences between chlorophyll and carotenoids contents for the photoperiods $24: 0$ and 16:08 light/dark are very small: $0.13 \mathrm{mg} \cdot \mathrm{g}^{-1}$ for chlorophyll and $0.04 \mathrm{mg} \cdot \mathrm{g}^{-1}$ for carotenoids. Overall, a lighting time of $16 \mathrm{~h}$ is optimal for obtaining high concentrations of photosynthetic pigments at high efficiency (Tab. 4).

Table 4 shows energy efficiencies of pigment production as a function of lighting time. We notice that lighting time of $16 \mathrm{~h}$ allows to have the highest energy efficiency for all pigments.

\section{Conclusion}

The effects of light intensity and photoperiod on biomass and pigment production of Spirulina platensis have been investigated. Absolute growth rates as well as energy efficiencies have been evaluated. While the highest productivity and specific growth rate is obtained for the highest light intensity $\left(160 \mu \mathrm{mol} \cdot \mathrm{m}^{-2} \cdot \mathrm{s}^{-1}\right)$, the best energy efficiency is obtained for the lowest light intensity $\left(80 \mu \mathrm{mol} \cdot \mathrm{m}^{-2} \cdot \mathrm{s}^{-1}\right)$ : this is true for biomass (energy efficiency is improved by $47 \%$ 
Table 4. Energetic efficiencies of pigment production and photoperiod.

\begin{tabular}{llcr}
\hline Photoperiod $(\mathrm{h}: \mathrm{h})$ & \multicolumn{2}{c}{ Energy efficiencies $\eta\left(\mathrm{mg} \cdot \mathrm{day}^{-1} \cdot \mathrm{kWh}^{-1}\right)$} \\
\cline { 2 - 4 } & Chl-a & Carotenoids & Phy \\
\hline $24: 00$ & $0.73 \pm 0.05$ & $0.23 \pm 0.03$ & $5.88 \pm 0.10$ \\
$20: 04$ & $0.59 \pm 0.03$ & $0.24 \pm 0.03$ & $4.93 \pm 0.13$ \\
$16: 08$ & $0.94 \pm 0.03$ & $0.31 \pm 0.03$ & $7.27 \pm 0.20$ \\
\hline
\end{tabular}

while productivity is lowered by $28 \%$ ) as well as for pigment production and more particularly for phycocyanin (energy efficiency is increased by $39 \%$ while productivity is lowered by $16 \%)$.

It has also been shown that applying a light intensity step after two days of cultivation improves the process energy efficiency while preserving high productivities for biomass. The positive effect of light intensity change on process energy efficiency for pigments production is not as significant than for biomass production. Nevertheless the principle of dynamically adjusting light intensity according for instance the optical density of the culture medium is promising and has to be investigated in more details.

Concerning photoperiod, results show that while biomass productivity and growth rate decrease with the illumination time, the process energy efficiency increases. As light intensity was constant during these experiments, energy efficiency improvement is attributed to biomass created during the dark phase. The best compromise between energy efficiency and productivity for biomass is obtained for a cycle of 20:04. For pigment production and more particularly phycocyanin, 16:08 cycle provides the best energy efficiency.

Acknowledgements. The authors acknowledge the Occitanie Region for its financial support through its regional development fund FEDER/ERDF (GREENALG projects).

Conflicts of interest. The authors declare that they have no known competing financial interests or personal relationships that could have appeared to influence the work reported in this paper.

\section{References}

Alves PLDCA, Magalhães ACN, Barja PR. 2002. The phenomenon of photoinhibition of photosynthesis and its importance in reforestation. Bot Rev 68(2): 193-208.

Amini Khoeyi Z, Seyfabadi J, Ramezanpour Z. 2012. Effect of light intensity and photoperiod on biomass and fatty acid composition of the microalgae, Chlorella vulgaris. Aquac Int 20(1): 41-49.

Becker EW. 2007. Micro-algae as a source of protein. Biotechnol Adv 25(2): 207-220.

Bennett A, Bogorad L. 1973 Complementary chromatic adaptation in a filamentous blue-green alga. J Cell Biol 58(2): 419-435.

Bezerra RP, Montoya EYO, Sato S, Perego P, de Carvalho JCM, Converti A. 2011. Effects of light intensity and dilution rate on the semicontinuous cultivation of Arthrospira (Spirulina) platensis. A kinetic monod-type approach. Bioresour Technol 102(3): 32153219 .
Bhat VB, Madyastha KM. 2000. C-Phycocyanin: A potent peroxyl radical scavenger in vivo and in vitro. Biochem Biophys Res Commun 275(1): 20-25.

Biggs W. 1986. Radiation measurement. In: Gensler WG, ed. Advanced agricultural instrumentation. Dordrecht (Netherlands): Springer, pp. 3-20.

Blanken W, Cuaresma M, Wijffels RH, Janssen M. 2013. Cultivation of microalgae on artificial light comes at a cost. Algal Res 2(4): 333-340.

Boussiba S, Richmond AE. 1980. C-phycocyanin as a storage protein in the blue-green alga Spirulina platensis. Arch Microbiol 125 (1-2): 143-147.

Carvalho AP, Silva SO, Baptista, JM, Malcata FX. 2011. Light requirements in microalgal photobioreactors: An overview of biophotonic aspects. Appl Microbiol Biotechnol 89(5): 12751288.

Chen HB, Wu JY, Wang CF, et al. 2010. Modelling on chlorophyll a and phycocyanin production by Spirulina platensis under various light-emitting diodes. Biochem Eng J 53(1): 52-56.

Chen CY, Kao PC, Tsai CJ, Lee DJ, Chang JS. 2013. Engineering strategies for simultaneous enhancement of C-phycocyanin production and $\mathrm{CO}_{2}$ fixation with Spirulina platensis. Bioresour Technol 145: 307-312.

Chen'v F, Zhang Y, Guo S. 1996. Growth and phycocyanin formation of Spirulina platensis in photoheterotrophic culture. Biotechnol Lett 18(5): 603-608.

Chojnacka K, Noworyta A. 2004. Evaluation of Spirulina sp. growth in photoautotrophic, heterotrophic and mixotrophic cultures. Enzyme Microb Technol 34(5): 461-465.

Danesi EDG, Rangel-Yagui CO, Carvalho JCM, Sato S. 2004. Effect of reducing the light intensity on the growth and production of chlorophyll by Spirulina platensis. Biomass Bioenergy 26(4): 329-335.

Danesi EDG, Rangel-Yagui CO, Sato S, Carvalho JCM. 2011. Growth and content of Spirulina platensis biomass chlorophyll cultivated at different values of light intensity and temperature using different nitrogen sources. Braz J Microbiol 42(1): 362 373.

Demmig-Adams B, Adams WW. 1992. Photoprotection and other responses of plants to high light stress. Ann Rev Plant Physiol Plant Mol Biol 43(1): 599-626.

Dubinsky Z. 2013. Photosynthesis. InTech. https://doi.org/10.5772/ 56742.

Galasso C, Gentile A, Orefice I, et al. 2019. Microalgal derivatives as potential nutraceutical and food supplements for human health: A focus on cancer prevention and interception. Nutrients 11(6): 1226.

Glemser M, Heining M, Schmidt J, et al. 2016. Application of lightemitting diodes (LEDs) in cultivation of phototrophic microalgae: Current state and perspectives. Appl Microbiol Biotechnol 100(3): 1077-1088. 
Hendry GAF, Houghton JD, Brown SB. 1987. The degradation of chlorophyll-a biological enigma. New Phytologist 107(2): 255302.

Koru E. 2012. Earth food Spirulina (Arthrospira): Production and quality standards. In: El-Samragy Y, ed. Food additive. InTech, pp. 191-202.

Kumar M, Kulshreshtha J, Singh GP. 2011. Growth and biopigment accumulation of cyanobacterium Spirulina platensis at different light intensities and temperature. Braz J Microbiol 42(3): 1128-1135.

Kumari A, Pathak AK, Guria C. 2015. Effect of light emitting diodes on the cultivation of Spirulina platensis using NPK-10:26:26 complex fertilizer: Spirulina growth in NPK fertilizer \& LED. Phycolog Res 63(4): 274-283.

Lee SH, Lee JE, Kim Y, Lee SY. 2016. The production of high purity phycocyanin by Spirulina platensis using light-emitting diodes based two-stage cultivation. Appl Biochem Biotechnol 178(2): 382-395.

Liao Q, Li L, Chen R, Zhu X. 2014. A novel photobioreactor generating the light/dark cycle to improve microalgae cultivation. Bioresour Technol 161: 186-191.

Lichtenthaler HK. 1987. Chlorophylls and carotenoids: Pigments of photosynthetic biomembranes. Meth Enzymol 148: 350-382.

Madhyastha HK, Vatsala TM. 2007. Pigment production in Spirulina fussiformis in different photophysical conditions. Biomol Eng 24 (3): 301-305.

Madhyastha HK, Sivashankari S, Vatsala TM. 2009. C-phycocyanin from Spirulina fussiformis exposed to blue light demonstrates higher efficacy of in vitro antioxidant activity. Biochem Eng J 43 (2): 221-224.

McCree KJ. 1971. The action spectrum, absorptance and quantum yield of photosynthesis in crop plants. Agric Meteorol 9: 191-216.

Niangoran U, Tian F, Canale L, Haba CT, Buso D, Zissis G. 2018. Study of the LEDs spectrums influence on the Spirulina platensis growth in batch culture. In: 2018 IEEE International Conference on Environment and Electrical Engineering and 2018 IEEE Industrial and Commercial Power Systems Europe (EEEIC/ I\&CPS Europe), pp. 1-4.

Pareek A, Srivastava P. 2001. Optimum photoperiod for the growth of Spirulina platensis. J Phytol Res 14(2): 219-220.

Patel AK, Jae MJ, Min EH, Sang JS. 2019. Effect of light conditions on mixotrophic cultivation of green microalgae. Bioresour Technol 282: 245-253.
Qiang H, Zarmi Y, Richmond A. 1998. Combined effects of light intensity, light-path and culture density on output rate of Spirulina platensis (Cyanobacteria). Eur J Phycol 33(2): 165-171.

Ravelonandro PH, Ratianarivo DH, Joannis-Cassan C, Isambert A, Raherimandimby M. 2008. Influence of light quality and intensity in the cultivation of Spirulina platensis from Toliara (Madagascar) in a closed system. J Chem Technol Biotechnol 83(6): 842-848.

Richmond A, Cheng-Wu Z, Zarmi Y. 2003. Efficient use of strong light for high photosynthetic productivity: Interrelationships between the optical path, the optimal population density and cellgrowth inhibition. Biomol Eng 20(4-6): 229-236.

Rizzo RF, dos Santos BDNC, de Castro GFPDS, et al. 2015. Production of phycobiliproteins by Arthrospira platensis under different lightconditions for application in food products. Food Sci Technol (Campinas) 35(2): 247-252.

Rodríguez-Concepcíon M, Avalos J, Bonet ML, et al. 2018. A global perspective on carotenoids: Metabolism, biotechnology, and benefits for nutrition and health. Progr Lipid Res 70: 62-93.

Romay C, Gonzalez R, Ledon N, Remirez D, Rimbau V. 2003. CPhycocyanin: A Biliprotein with Antioxidant, Anti-Inflammatory and Neuroprotective Effects. Curr Protein Peptide Sci 4(3): 207216.

Schulze PSC, Barreira LA, Pereira HGC, Perales JA, Varela JCS. 2014. Light emitting diodes (LEDs) applied to microalgal production. Trends Biotechnol 32(8): 422-430.

Tian F, Buso D, Wang T, Lopes M, Niangoran U, Zissis G. 2018. Effect of Red and Blue LEDs on the production of phycocyanin by Spirulina platensis based on photosynthetically active radiation. J Sci Technol Light 41(0): 148-152.

Wahidin S, Idris A, Shaleh SRM. 2013. The influence of light intensity and photoperiod on the growth and lipid content of microalgae Nannochloropsis sp. Bioresour Technol 129: 7-11.

Wang CY, Fu CC, Liu YC. 2007. Effects of using light-emitting diodes on the cultivation of Spirulina platensis. Biochem Eng J 37 (1): 21-25.

Xue S, Su Z, Cong W. 2011. Growth of Spirulina platensis enhanced under intermittent illumination. J Biotechnol 151(3): 271-277.

Zarrouk C. 1966. Contribution à l'étude d'une cyanophycée Influence de divers facteurs physiques et chimiques sur la croissance et la photosynthèse de Spirulina maxima (Setch et Gardner) Geitler. Université de Paris.

Cite this article as: Niangoran NUF, Buso D, Zissis G, Prudhomme T. 2021. Influence of light intensity and photoperiod on energy efficiency of biomass and pigment production of Spirulina (Arthrospira platensis). OCL 28: 37. 